\title{
Profile of Matrix Metalloproteinase Activity, Markers of Collagen and Elastin Degradation and Remodeling During Pregnancy, Delivery, and Puerperium in Pelvic Organ Prolapse 3 Months After Childbirth
}

Tyas Priyatini ( $\nabla$ tyasprytn@gmail.com ) Universitas Indonesia Fakultas Kedokteran https://orcid.org/0000-0003-3330-9824

\section{Budi Iman Santoso}

Universitas Indonesia Fakultas Kedokteran

Trika Irianta

Universitas Hasanuddin Fakultas Kedokteran

Herqutanto .

Universitas Indonesia Fakultas Kedokteran

Nuryati Chairani Siregar

Universitas Indonesia Fakultas Kedokteran

Alida Harahap

Universitas Indonesia Fakultas Kedokteran

Mohamad Sadikin

Universitas Indonesia Fakultas Kedokteran

Research

Keywords: pelvic organ prolapse, MMP-9, collagen, elastin

Posted Date: September 20th, 2021

DOI: https://doi.org/10.21203/rs.3.rs-882542/v1

License: (a) (1) This work is licensed under a Creative Commons Attribution 4.0 International License.

Read Full License 


\section{Abstract}

Introduction: Pelvic organ prolapse (POP) is a common condition that negatively impacts the quality of life of millions of women. Recent results indicate that a burst of elastic fiber assembly and cross-linking occurs in the vaginal wall postpartum and that synthesis and assembly of elastic fibers are crucial for the recovery of pelvic organ support after vaginal delivery.

Methods: A total of 39 primigravida women with gestational age $>36$ weeks who underwent vaginal delivery were included in this study. Blood and urine samples were taken for laboratory assessment including carboxyl-terminal telopeptide of the type I collagen (ICTP), procollagen type I N-propeptide (PINP), procollagen type-III N-propeptide (PIIINP), desmosine, tropoelastin, and matrix metalloproteinase-9 (MMP-9). At $24 \otimes 48$ hours after labor, the subject was observed in the treatment room and a second blood sample was taken for the examination. At 6 weeks post-partum, a third blood sample was taken for examination.

Results: There was a significant relationship between serum MMP-9 levels six weeks post-partum in the pelvic floor dysfunction group and the control group $(p=0.025)$. In addition, a significant difference was also found in the different levels of MMP-9 $(p=0.041)$ and tropoelastin $(p=0.041)$ during delivery and 6 weeks after delivery. There was a significant difference between serum ICTP levels at delivery in the cystocele and control groups $(p=0.042), \operatorname{ICTP}(p=0.019)$ and tropoelastin $(p=0.046)$ levels also differ significantly during delivery and 6 weeks after delivery.

Conclusion: ICTP, MMP-9, and tropoelastin are potential biomarkers in association with pelvic organ prolapse.

\section{Introduction}

Pelvic organ prolapse (POP) is a common condition that negatively impacts the quality of life of millions of women. ${ }^{1}$ The etiology of this condition is multifactorial. Pregnancy, labor, and delivery are known to be the most prominent factor associated with the development of pelvic organ prolapse. ${ }^{2}$ However, the mechanisms by which pregnancy and parturition lead to failure of pelvic organ support are not known. It has been hypothesized that pregnancy itself can cause pelvic floor dysfunction due to maternal hormonal adaptation that can cause changes in pelvic floor structures to accommodate delivery of a baby and also by mechanical forces of the gravid uterus and the fetus that can cause downward pressure to the pelvic floor. Furthermore, parturition can induce injury of the pelvic floor muscle and vaginal fibroelastic tissue. Stretch injury to the pelvic floor muscle and vagina during childbirth can activate proteases in the vaginal wall and its supportive tissues leading to degradation of fibroelastic fiber such as collagen and elastin.

After delivery pelvic floor undergoes a healing process to regain its strength to keep the pelvic organ in place and ensure its function. The specific process and regulation of protease and remodeling of 
collagen and elastin during pregnancy, delivery, and puerperium are not well defined, and there is little information regarding this process especially in humans.

Recent results indicate that a burst of elastic fiber assembly and cross-linking occurs in the vaginal wall postpartum and that synthesis and assembly of elastic fibers are crucial for the recovery of pelvic organ support after vaginal delivery. ${ }^{3}$ Based on the relationship between failed collagen and elastic fiber synthesis and pelvic organ prolapse, we suggest that extracellular matrix degradation occurs in the vaginal wall during delivery and the remodeling process might have been failed to restore the supporting function of the pelvic floor after parturition, thereby leading to pelvic organ prolapse. Although many studies have been done in mice, the mechanisms of pelvic organ prolapse may be unique in women.

\section{Material And Methods}

The study was conducted in National Referral Hospital in Jakarta starting from January 2015 to July 2019. It was performed using a nested case-control study design. Patients were recruited based on the inclusion criteria. A total of 39 primigravida women with gestational age $>36$ weeks who underwent vaginal delivery were included in this study. Women who had a history of surgery, pelvic floor dysfunction before pregnancy, suffered from malignancy, chronic lung disease, coronary heart disease, diabetes mellitus, severe malnutrition, labor-associated urinary tract infection, and levator ani avulsion were excluded from this study. Patients were considered as drop out if they were not able to be followed up in 12 weeks after labor, suffered from severe labor complications such as postpartum hemorrhage and sepsis, and finished their labor with caesarean section.

Pregnant women who have agreed to participate in the study were asked for a consent. After the pregnant women signed a statement of consent to participate in the study, blood and urine samples were taken for laboratory assessment including carboxyl-terminal telopeptide of the type I collagen (ICTP), procollagen type I N-propeptide (PINP), procollagen type-III N-propeptide (PIIINP), desmosine, tropoelastin, and matrix metalloproteinase-9 (MMP-9). If the results of the urinalysis show that the subject has a urinary tract infection, the subject will receive antibiotic therapy before delivery. After antibiotic therapy, urinalysis was repeated in 7 days to rule out infection. Once it was confirmed that there was no infection, the subject could be included in the study.

At $24 \square 48$ hours after delivery, the subject was observed in the treatment room, a second blood sample was taken for the examination of ICTP, PINP, PIIINP, desmosine, tropoelastin, and MMP-9. Blood samples were taken from morning to evening (working hours). At 6 weeks after delivery, a third blood sample was taken for examination of ICTP, PINP, PIIINP, desmosine, tropoelastin, and MMP9. The samples were stored at $-80^{\circ} \mathrm{C}$ using ELISA kit that has coefficient of variation $<10 \%$.

In 3 months postpartum, POP was evaluated using POP-Q questionnaire. Data analysis was carried out using the SPSS 20 program. Univariate analysis was carried out on each variable, categorical variables were presented in terms of frequency and percentage, while numerical variables were presented in the 
form of the median (minimum-maximum). Mann Whitney test was performed to compare the median differences between biomarkers measured in pelvic floor dysfunction and control group. This analysis was also performed to compare those variables in the cystocele group.

\section{Results}

Patients' demographic data are shown in Table 1. The median values for the degradation and synthesis markers of collagen, elastin, and serum MMP-9 enzymes during pregnancy, after delivery, and 6 weeks postpartum are shown in Table 2. The median difference is quite large in serum MMP-9 and ICTP levels between pregnancy and 24-48 hours after delivery, levels decrease at six weeks postpartum.

Table 1

Demographic Data of The Patients

\begin{tabular}{|lll|}
\hline & Median $(\mathrm{N}=39)$ & Range \\
\hline Age (year) & 24 & $18-34$ \\
\hline Weight $(\mathrm{kg})$ & 60 & $44-94$ \\
\hline Height $(\mathrm{m})$ & 1.56 & $1.49-1.7$ \\
\hline BMR $\left(\mathrm{kg} / \mathrm{m}^{2}\right)$ & 25.39 & $17.18-40.1$ \\
\hline Newborn weight $(\mathrm{g})$ & 3000 & $2300-3900$ \\
\hline
\end{tabular}

Table 2

Differences in median serum markers levels of degradation and synthesis of collagen, elastin, and MMP-9 during pregnancy, after delivery, and 6 weeks postpartum

\begin{tabular}{|lllllll|}
\hline \multirow{2}{*}{ Biomarker } & \multicolumn{2}{l}{ Pregnancy } & \multicolumn{2}{l}{ After Delivery } & \multicolumn{2}{l|}{ Six Weeks Post-Partum } \\
\cline { 2 - 7 } & Median & Range & Median & Range & Median & Range \\
\hline ICTP & 62.94 & $3.33,293.09$ & 123.75 & $12.99,457.06$ & 105.82 & $1.59,231.45$ \\
\hline PINP & 128.64 & $8.63,712.1$ & 107.35 & $7.5,625.1$ & 104.44 & $5.02,663.75$ \\
\hline PIIINP & 262.12 & $28.73,706.78$ & 267.96 & $50.19,685.9$ & 175.89 & $33.57,557.71$ \\
\hline Desmosin & 0.98 & $0.37,22.04$ & 1.12 & $0.46,26$ & 1.14 & $0.3,103.7$ \\
\hline MMP9 & 580.3 & $147.9,1898.1$ & 1056.8 & $158.5,1964$ & 418.2 & $57.9,1770$ \\
\hline Tropoelastin & 0.83 & $0.1,18.22$ & 0.97 & $0.1,17.35$ & 0.71 & $0.09,5.95$ \\
\hline
\end{tabular}


The median distribution of differences in levels of markers ICTP, PINP, PIIINP, desmosine, tropoelastin, and MMP-9 is shown in Table 3. The median difference in levels of markers of degradation of collagen I (ICTP) and MMP-9 was higher after delivery than during pregnancy except for desmosin and PINP. All marker levels decreased after six weeks postpartum.

Table 3

The distribution of the difference in levels of markers during pregnancy, after delivery, and 6 weeks after delivery

\begin{tabular}{|lllll|}
\hline Difference & \multicolumn{2}{l}{ During pregnancy and after delivery } & \multicolumn{2}{l|}{ After delivery and 6 weeks post-partum } \\
\cline { 2 - 5 }$(\mathrm{ng} / \mathrm{mL})$ & Median & Range & Median & Range \\
\hline Delta ICTP & 54.04 & $-80.92,292.2$ & -36.18 & $-344.8,153.57$ \\
\hline Delta PINP & -23.35 & $-170.87,187.8$ & -5.42 & $-274.59,123.89$ \\
\hline Delta PIIINP & -13.73 & $-205.2,168,12$ & -33.79 & $-247.81,190.39$ \\
\hline Delta Desmosin & 0.11 & $-16.3,-739.5$ & -0.09 & $-18.86,102.97$ \\
\hline Delta MMP9 & 437.5 & $-739.5,1492.9$ & -616.2 & $-1519.1,264.3$ \\
\hline Delta Tropoelastin & 0.0 & $-6.18,4.66$ & -0.24 & $-16.82,1.26$ \\
\hline
\end{tabular}

Bivariate analysis was performed on levels of markers of degradation and synthesis of collagen I, III, and elastin, as well as levels of MMP-9 with the incidence of grade 2 POP in one or more compartments (Table 4). There was a significant relationship between serum MMP-9 levels six weeks post-partum in the pelvic floor dysfunction group and the control group $(p=0.025)$. In addition, a significant difference was also found in the different levels of MMP-9 $(p=0.041)$ and tropoelastin $(p=0.041)$ during delivery and 6 weeks after delivery. 
Table 4

Differences in median levels of markers of degradation and synthesis of collagen, elastin, and serum MMP-9 in the POP group and the control group.

\begin{tabular}{|c|c|c|c|c|c|}
\hline \multirow[t]{2}{*}{ Markers } & \multicolumn{2}{|c|}{ POP $(n=22)$} & \multicolumn{2}{|c|}{ Control $(n=17)$} & \multirow[t]{2}{*}{$\mathbf{p}$} \\
\hline & Med & Range & Med & Range & \\
\hline ICTP pre $(\mathrm{ng} / \mathrm{mL})$ & 61.015 & $3.33,226.33$ & 62.94 & $5.82,293.09$ & 0.671 \\
\hline PINP pre (ng/mL) & 274.71 & $8.63,711.24$ & 104.44 & $15.83,712.1$ & 0.269 \\
\hline PIIINP pre (ng/mL) & 307.05 & $28.73,706.78$ & 217.1 & $\begin{array}{l}80.13 \\
531.13\end{array}$ & 0.336 \\
\hline Desmosin pre (ng/mL) & 1.3 & $0.41,22.04$ & 0.97 & $0.37,8.5$ & 0.197 \\
\hline MMP9 pre (ng/mL) & 553.95 & $147.9,1898.1$ & 591.6 & $268.4,889.5$ & 0.843 \\
\hline Tropoelastin pre (ng/mL) & 8.965 & $0.12,18.15$ & 0.72 & $0.1,18.22$ & 0.165 \\
\hline ICTP labor (ng/mL) & 113.31 & $12.99,350.43$ & 155.07 & $\begin{array}{l}30.13 \\
457.06\end{array}$ & 0.269 \\
\hline PINP labor (ng/mL) & 283.465 & $7.5,625.1$ & 93.99 & $8.71,577.6$ & 0.183 \\
\hline PIIINP labor (ng/mL) & 261.38 & $50.19,685.9$ & 267.96 & $66.4,504.12$ & 0.865 \\
\hline Desmosin labor (ng/mL) & 1.615 & $0.51,26$ & 1.08 & $0.46,9.08$ & 0.116 \\
\hline MMP9 labor (ng/mL) & 1089.65 & $231.6,1964$ & 959.9 & $\begin{array}{l}158.5 \\
1689.8\end{array}$ & 0.365 \\
\hline Tropoelastin labor (ng/mL) & 4.8 & $0.15,17.35$ & 0.7 & $0.1,17.12$ & 0.097 \\
\hline ICTP 6 weeks (ng/mL) & 96.11 & $1.59,231.45$ & 112.26 & $3.1,206.99$ & 0.955 \\
\hline PINP 6 weeks (ng/mL) & 223.88 & $5.02,663.75$ & 78.24 & $\begin{array}{l}11.75 \\
514.44\end{array}$ & 0.149 \\
\hline PIIINP 6 weeks (ng/mL) & 201.41 & $34.61,557.71$ & 156.12 & $\begin{array}{l}33.57 \\
485.89\end{array}$ & 0.396 \\
\hline Desmosin 6 weeks $(\mathrm{ng} / \mathrm{mL})$ & 1.51 & $0.31,27.93$ & 1.05 & $0.3,103.7$ & 0.671 \\
\hline MMP9 6 weeks (ng/mL) & 352.5 & $57.9,1124.1$ & 531.5 & $90.9,1770$ & 0.025 \\
\hline Tropoelastin 6 weeks $(\mathrm{ng} / \mathrm{mL})$ & 0.685 & $0.11,5.95$ & 0.74 & $0.09,1.48$ & 0.640 \\
\hline Delta ICTP $(\mathrm{ng} / \mathrm{mL})$ pre-labor & 53.57 & $\begin{array}{l}-80.92 \\
181.98\end{array}$ & 61.7 & $-14.69,290.2$ & 0.322 \\
\hline Delta PINP (ng/mL) pre-labor & -24.35 & $\begin{array}{l}-170.87 \\
187.8\end{array}$ & -14.23 & $-134.5,61.71$ & 0.977 \\
\hline
\end{tabular}




\begin{tabular}{|c|c|c|c|c|c|}
\hline \multirow[t]{2}{*}{ Markers } & \multicolumn{2}{|c|}{ POP $(n=22)$} & \multicolumn{2}{|c|}{ Control $(n=17)$} & \multirow[t]{2}{*}{$\mathbf{p}$} \\
\hline & Med & Range & Med & Range & \\
\hline Delta PIIINP $(\mathrm{ng} / \mathrm{mL})$ pre-labor & -32.98 & $\begin{array}{l}-205.2 \\
133.76\end{array}$ & -7.8 & $\begin{array}{l}-81.84 \\
168.12\end{array}$ & 0.074 \\
\hline Delta desmosin $(\mathrm{ng} / \mathrm{mL})$ pre-labor & 0.115 & $-16.3,12.15$ & 0.11 & $-1.75,8.12$ & 0.854 \\
\hline Delta MMP9 $(\mathrm{ng} / \mathrm{mL})$ pre-labor & 450.8 & $\begin{array}{l}-739.5 \\
1492.9\end{array}$ & 309.9 & $-421.8,870$ & 0.65 \\
\hline Delta tropoelastin $(\mathrm{ng} / \mathrm{mL})$ pre-labor & -0.025 & $-6.18,4.66$ & 0 & $-1.51,0.27$ & 0.81 \\
\hline Delta ICTP $(\mathrm{ng} / \mathrm{mL})$ labor- 6 weeks & -21.53 & $\begin{array}{l}-244.61 \\
153.57\end{array}$ & -44.3 & $-344.8,142.6$ & 0.213 \\
\hline Delta PINP (ng/mL) labor- 6 weeks & -0.045 & $\begin{array}{l}-274.59 \\
123.89\end{array}$ & -21.56 & $\begin{array}{l}-125.46 \\
76.64\end{array}$ & 0.581 \\
\hline Delta PIIINP (ng/mL) labor-labor & -14.98 & $\begin{array}{l}-247.81 \\
190.39\end{array}$ & -51.82 & $\begin{array}{l}-233.21 \\
184.84\end{array}$ & 0.35 \\
\hline Delta desmosin $(\mathrm{ng} / \mathrm{mL})$ labor-labor & -0.305 & $-18.86,24.63$ & 0.02 & $-3.31,102.97$ & 0.106 \\
\hline Delta MMP9 $(\mathrm{ng} / \mathrm{mL})$ labor- 6 weeks & -683.2 & $\begin{array}{l}-1519.1 \\
264.3\end{array}$ & -394.3 & $-1046.4,252$ & 0.041 \\
\hline $\begin{array}{l}\text { Delta tropoelastin }(\mathrm{ng} / \mathrm{mL}) \text { labor- } 6 \\
\text { weeks }\end{array}$ & -3.98 & $-16.71,1.26$ & -0.04 & $-16.82,0.53$ & 0.041 \\
\hline
\end{tabular}

The bivariate test was performed on subjects with grade 2 or more cystocele without including subjects who had combined POP in the anterior and posterior compartments and as controls were subjects without grade 2 cystocele (Table 5). In this bivariate test, there was a significant difference between serum ICTP levels at delivery in the cystocele and control groups $(p=0.042)$. In addition, a significant difference was also found in the difference in ICTP $(p=0.019)$ and tropoelastin levels during delivery and 6 weeks after delivery $(p=0.046)$. 
Table 5

Differences in median levels of markers of degradation and synthesis of collagen, elastin, and serum MMP-9 in the cystocele group and the control group.

\begin{tabular}{|c|c|c|c|c|c|}
\hline \multirow[t]{2}{*}{ Markers } & \multicolumn{2}{|c|}{ Cystocele $(n=12)$} & \multicolumn{2}{|c|}{ Control $(n=17)$} & \multirow[t]{2}{*}{$\mathbf{p}$} \\
\hline & Med & Range & Med & Range & \\
\hline ICTP pre $(\mathrm{ng} / \mathrm{mL})$ & 40.03 & $3.33,158.32$ & 62.94 & $5.82,293.09$ & 0.232 \\
\hline PINP pre (ng/mL) & 309.16 & $10.44,674.92$ & 104.44 & $15.83,712.1$ & 0.132 \\
\hline PIIINP pre (ng/mL) & 328.89 & $28.73,706.78$ & 217.1 & $\begin{array}{l}80.13 \\
531.13\end{array}$ & 0.101 \\
\hline Desmosin pre (ng/mL) & 1.395 & $0.57,22.04$ & 0.97 & $0.37,8.5$ & 0.121 \\
\hline MMP9 pre (ng/mL) & 560.7 & $257.8,1898.1$ & 591.6 & $268.4,889.5$ & 0.929 \\
\hline Tropoelastin pre $(\mathrm{ng} / \mathrm{mL})$ & 12.27 & $0.12,18.15$ & 0.72 & $0.1,18.22$ & 0.116 \\
\hline ICTP labor (ng/mL) & 73.61 & $12.99,236.2$ & 155.07 & $\begin{array}{l}30.13 \\
457.06\end{array}$ & 0.042 \\
\hline PINP labor (ng/mL) & 283.46 & $7.95,625.1$ & 93.99 & $8.71,577.6$ & 0.057 \\
\hline PIIINP labor (ng/mL) & 301.27 & $68.4,685.9$ & 267.96 & $66.4,504.12$ & 0.376 \\
\hline Desmosin labor $(\mathrm{ng} / \mathrm{mL})$ & 1.38 & $0.62,0.26$ & 1.08 & $0.46,9.08$ & 0.241 \\
\hline MMP9 labor (ng/mL) & 1084.7 & $468.3,1907.1$ & 959.9 & $\begin{array}{l}158.5 \\
1698.8\end{array}$ & 0.425 \\
\hline Tropoelastin labor (ng/mL) & 9.41 & $0.18,17.35$ & 0.7 & $0.1,17.12$ & 0.177 \\
\hline ICTP 6 weeks (ng/mL) & 96.99 & $6.26,231.45$ & 112.26 & $3.1,206.99$ & 0.79 \\
\hline PINP 6 weeks (ng/mL) & 223.885 & $5.02,510.27$ & 78.24 & $\begin{array}{l}11.75 \\
514.44\end{array}$ & 0.215 \\
\hline PIIINP 6 weeks $(\mathrm{ng} / \mathrm{mL})$ & 193.82 & $34.61,506.21$ & 156.12 & $\begin{array}{l}33.57 \\
485.89\end{array}$ & 0.535 \\
\hline Desmosin 6 weeks $(\mathrm{ng} / \mathrm{mL})$ & 1.33 & $0.31,27.93$ & 1.05 & $0.3,103.7$ & 0.757 \\
\hline MMP9 6 weeks (ng/mL) & 423.65 & $121.7,1124.1$ & 531.5 & $90.9,1770$ & 0.376 \\
\hline Tropoelastin 6 weeks $(\mathrm{ng} / \mathrm{mL})$ & 0.7 & $0.11,5.95$ & 0.74 & $0.09,1.48$ & 0.58 \\
\hline Delta ICTP $(\mathrm{ng} / \mathrm{mL})$ pre-labor & 29.94 & $\begin{array}{l}-80.92, \\
155.05\end{array}$ & 61.7 & $-14.69,290.2$ & 0.092 \\
\hline Delta PINP (ng/mL) pre-labor & -27.9 & $\begin{array}{l}-135.95 \\
105.97\end{array}$ & -14.23 & $-134.5,51.71$ & 0.929 \\
\hline
\end{tabular}




\begin{tabular}{|c|c|c|c|c|c|}
\hline \multirow[t]{2}{*}{ Markers } & \multicolumn{2}{|c|}{ Cystocele $(n=12)$} & \multicolumn{2}{|c|}{ Control $(n=17)$} & \multirow[t]{2}{*}{ p } \\
\hline & Med & Range & Med & Range & \\
\hline Delta PIIINP (ng/mL) pre-labor & -7.68 & $\begin{array}{l}-205.2 \\
133.76\end{array}$ & -7.8 & $\begin{array}{l}-81.84 \\
168.12\end{array}$ & 0.452 \\
\hline Delta desmosin $(\mathrm{ng} / \mathrm{mL})$ pre-labor & 0.1 & $-16.3,12.15$ & 0.11 & $-1.75,8.12$ & 0.773 \\
\hline Delta MMP9 $(\mathrm{ng} / \mathrm{mL})$ pre-labor & 407.15 & $\begin{array}{l}-739.5 \\
1492.9\end{array}$ & 309.9 & $-421.8,870$ & 0.79 \\
\hline Delta tropoelastin $(\mathrm{ng} / \mathrm{mL})$ pre-labor & -0.15 & $-6.18,4.66$ & 0 & $-1.51,0.27$ & 0.929 \\
\hline Delta ICTP (ng/mL) labor-6 weeks & 21.21 & $\begin{array}{l}-151.92 \\
153.57\end{array}$ & -44.3 & $-344.8,142.6$ & 0.019 \\
\hline Delta PINP (ng/mL) labor-6 weeks & -21.97 & $\begin{array}{l}-274.59 \\
67.27\end{array}$ & -21.56 & $\begin{array}{l}-125.46 \\
76.64\end{array}$ & 0.507 \\
\hline Delta PIIINP (ng/mL) labor-labor & -80.37 & $\begin{array}{l}-247.81 \\
47.88\end{array}$ & -51.82 & $\begin{array}{l}-233.21 \\
184.84\end{array}$ & 0.69 \\
\hline Delta desmosin $(\mathrm{ng} / \mathrm{mL})$ labor-labor & -0.26 & $-18.89,24.63$ & 0.02 & $-3.31,102.97$ & 0.268 \\
\hline Delta MMP9 $(\mathrm{ng} / \mathrm{mL})$ labor-6 weeks & -675.2 & $\begin{array}{l}-1519.1 \\
264.3\end{array}$ & -394.3 & $-1046.4,252$ & 0.132 \\
\hline $\begin{array}{l}\text { Delta tropoelastin }(\mathrm{ng} / \mathrm{mL}) \text { labor- } 6 \\
\text { weeks }\end{array}$ & -8.22 & $-16.71,0.04$ & -0.04 & $-16.82,0.53$ & 0.046 \\
\hline
\end{tabular}

In addition, a graph is presented to identify the changes in biomarker levels between treatment groups. The trend of changes in biomarker levels between the pelvic floor dysfunction group, cystocele, and control group in pregnancy, labor, and 6 weeks postpartum is presented in Fig. 1.

\section{Discussion}

\section{Pregnancy}

PINP, PIIINP, and Desmosin levels were relatively higher in pregnancy, while on the other hand, tropoelastin level was lower in POP groups compared to control groups, although the results were not statistically significant. On the other hand, ICTP and MMP-9, which are relative degradation markers, have similar levels in both groups.

The increased of PINP and PIIINP levels during pregnancy are due to the process of rapid increase in the weight and size of the uterus due to deposition of collagen and elastin. In human, it increases around 11 times to accommodate fetal growth. ${ }^{4}$ In addition, Tropoelastin level during pregnancy was lower in POP groups compared to control groups. 
All the biomarkers in this research were taken from the last trimester patient who are not yet in labor so that it could be seen from the profile that the degradation process (the increased of MMP-9 and ICTP level) has not yet happened.

\section{Post-partum}

MMP-9 level was not relatively different between POP groups and control groups. In 24-48 hours postpartum, MMP-9 level increased in all groups. Six weeks postpartum, MMP-9 level decreased in all groups, however the decrease was clinically significant in POP groups compared to control groups. The results of this study are similar to the study conducted by Cecilia et al which showed that MMP-9 mRNA activity increased more than 10-fold at 24-48 hours after delivery. MMP-9 is a protease enzyme that plays a role in the degradation of collagen and elastin. ${ }^{5}$ The stretch of the vaginal wall during labor initiates the degradation of collagen and elastin tissue which is mediated by protease enzyme activity, this will lead to an increase in the degradation of collagen which is the main component of the vaginal wall. thereby increasing the weakness of the pelvic organ support systems. ${ }^{6}$

Elastin is responsible for the distensibility and ability of the tissue to return to its initial length before stretching. In the last trimester of pregnancy, there is an increase in elastin synthesis which causes an increase in pelvic floor distensibility to facilitate labor. After delivery, increased synthesis of tropoelastin and fibulin- 5 is required to repair elastin fiber damage caused by vaginal delivery and regenerate elastic fibers in vaginal tissue. Disruption of elastin homeostasis in vaginal tissue after delivery may be a contributing factor in the incidence of POP after delivery. ${ }^{7}$ Jameson et al conducted a study on postnatal rat models, the results of this study showed that POP after delivery was associated with changes in elastin structure and lower elastin degradation leading to the accumulation of damaged elastin fibers compared to the amount of new elastin fiber formation. Jameson concluded that POP after delivery occurs due to the inability to process the molecular mechanisms required to destroy damaged elastin fibers in the pelvic floor tissue as a result of childbirth. ${ }^{8}$

Desmosine level increased during pregnancy, however it was not significantly different between POP groups and control groups. Then, during 24-48 postpartum, desmosine levels increase but not significantly different in POP groups compared to control groups.

ICTP levels increase but not significantly different in POP groups compared to control groups. This result was similar with Oksana et al study which reported increasing level of elastin, collagen type I, and collagen type III during pregnancy. In this stage, myometrium remodeling occurs and causes partial degradation of collagen fibers, resulting an increase of extracellular matrix synthesis. ${ }^{9}$

PINP level was relatively constant in POP groups and PIIINP level decrease in 24-48 postpartum compared with during pregnancy. PINP level was slightly higher, while tropoelastin level decrease in POP groups, however the level was still higher than control groups although it was not statistically significant. 
Biomarker profile during 24-48 hours post-partum shows the domination of degradation marker both collagen and elastin. This explains degradation process of collagen and elastin due to the effects of labor. In POP group, the increase of MMP-9 was significantly higher compared to control group might be due to collagen and elastin degradation process that was higher in POP group.

\section{Six weeks post-partum}

Six weeks post-partum, PINP level was higher in POP group compared to the control group although it was not statistically significant. During this time, both PINP, PIIINP, and tropoelastin levels decrease compared to 24-48 postpartum. Tropoelastin level decreased significantly in POP group compared to the control group. The healing process that caused by injury during labor might appear six weeks postpartum. Type I collagen is a type of collagen that is stronger and less stretchable than type III collagen. The relationship between POP and an increase in PINP which appears in this study is supported by the study of Zhou L et al. ${ }^{10}$ Zhou $L$ et al. performed vaginal stiffness analysis and vaginal wall biopsy to assess the density of collagen I and III in premenopausal and menopausal patients who experienced POP with the results that the vaginas of patients with POP were stiffer and had lower collagen III density than controls. The study by Zhou et al. is consistent with several other studies which have shown that the vaginas of patients with POP are stiffer than controls and that there is an increase in the collagen $\mathrm{I} / \mathrm{III}$ ratio. It also appears in histopathological studies that collagen fibers in POP sufferers are thicker and wider with more irregular fiber patterns. ${ }^{11-14}$

MMP-9 and ICTP levels in POP group were lower compared to the control group. However, only MMP-9 level differed significantly in both groups. ICTP levels decrease in POP and cystocele groups compared to control groups into the same point. Desmosine levels during six weeks post-partum were not differ in both groups. Desmosine levels decrease in POP and cystocele groups compared to control groups into the same point. These results were supported by Drewes et al study which reported that levels of desmosine (a marker of degradation of the maturing elastin fiber) will increase in the vaginal tissue 48 hours to 7 days after delivery. ${ }^{15}$

When compared to 24-48 hours post-partum, MMP-9 and ICTP decreased during six weeks post-partum, meanwhile desmosine levels remained the same. MMP-9 decreased significantly in POP group compared to control groups.

This study is a prospective cohort study looking at all markers of both collagen and elastin degradation and remodeling. Despite having strict inclusion and exclusion criteria, this study has some limitations. First, the sample size of this study is small. Second, the best time to take a blood sample is not yet known to better describe the process that occurs. Third, vaginal tissue biopsy was not performed to see local tissue conditions and compared with systemic markers due to ethical consideration. Therefore, the authors suggest that the study be continued with larger sample size. In addition, the second blood draw (24-48 hours after delivery) is only to see the magnitude of the degradation process, while to see the remodeling process, blood collection can be done after 3 days to 2 weeks after delivery. 


\section{Conclusion}

ICTP, MMP-9, and tropoelastin are potential biomarkers in association with pelvic organ prolapse. The authors suggest that the study be continued with larger sample size. In addition, the second blood draw (24-48 hours after delivery) is only to see the magnitude of the degradation process, while to see the remodeling process, blood collection can be done after 3 days to 2 weeks after delivery.

\section{Abbreviations}

POP: Pelvic organ prolapse; ICTP: carboxyl-terminal telopeptide of the type I collagen; PINP: procollagen type I N-propeptide; PIIINP: procollagen type-III N-propeptide; MMP-9: matrix metalloproteinase-9

\section{Declarations}

\section{Availability of data and materials}

All data generated or analyzed during this study are included in this published article

\section{Ethics approval and consent to participate}

This study was approved and given the ethical approval by Health Research Ethics Committee, Faculty of Medicine Universitas Indonesia, Cipto Mangunkusumo Hospital No. 179/UN2.F1/ETIK/2015. Written consent for participation and data presentation was collected and received from the patients who had agreed to take part in the study.

\section{Consent for publication}

Not applicable

\section{Competing interests}

The authors declare that they have no competing interests

\section{Funding}

This work used personal expenses of the authors

\section{Authors' contributions}

TP is the major contributor in writing the manuscript. TP, BIS, TI, H, NS, AH, MS planned and evaluate the study. $\mathrm{H}$ performed the statistical analysis.

\section{Acknowledgements}

We acknowledge Herqutanto for statistical analysis assistance. 


\section{References}

1. Nygaard I, Barber MD, Burgio KL, Kenton K, Meikle S, Schaffer J, Spino C, Whitehead WE, Wu J, Brody DJ; Pelvic Floor Disorders Network. Prevalence of symptomatic pelvic floor disorders in US women. JAMA. 2008 Sep 17;300(11):1311-6.

2. Handa VL, Blomquist JL, Knoepp LR, Hoskey KA, McDermot KC, Munoz A. Pelvic floor disorders 5-10 years after vaginal or cesarean childbirth. Obstet Gynecol. 2011;118(4):777-84.

3. Drewes PG, Marinis SI, Acevedo J, Keller P, Schaffer JI, Word RA. Paper 17: Regulation of lysyl oxidase in the vaginal wall: role of estrogen, progesterone, and pregnancy. Journal of Pelvic Medicine and Surgery. 2005;11: S8-S9.

4. Chvapil M. Physiology of connective tissue. London: Butterworths; 1967.

5. Cecilia KW, Marinis SI, Drewes PG, Keller PW, Acevedo JF, RA W. Regulation of Elastolytic Protease in the Mouse Vagina During Pregnancy, Parturition, and Puerperium. Biol Reprod. 2008;78:521-8.153.

6. Zong W, Jallah ZC, SE S. Repetitive mechanical stretch increases extracellular collagenase activity in vaginal fibroblasts. Female Pelvic Med Reconstr Surg. 2010;16:257-62.

7. Söderberg MW, Falconer C, Byström B, Malmström A, Ekman G. Young women with genital prolapse have a low collagen concentration. Acta Obstetricia et Gynecologica Scandinavica. 2004;83(12):1193-8.

8. Jameson SA, Swaminathan G, Dahal S, Couri B, Kuang M, Rietsch A, et al. Elastin homeostasis is altered with pelvic organ prolapse in cultures of vaginal cells from a lysyl oxidase-like 1 knockout mouse model. Physiological Reports. 2020;8(11).

9. Shynlova O, Mitchell JA, Tsampalieros A, Langille BL, Lye SJ. Progesterone and gravidity differentially regulate expression of extracellular matrix components in the pregnant rat myometrium. Biol Reprod. 2004 Apr;70(4):986-92.

10. Zhou L, Lee JH, Wen Y, Constantinou C, Yoshinobu M, Omata S, et al. Biomechanical Properties and Associated Collagen Composition in Vaginal Tissue of Women with Pelvic Organ Prolapse. Journal of Urology. 2012;188(3):875-80.

11. Sun M-J, Cheng Y-S, Sun R, Cheng W-L, Liu C-s. Changes in mitochondrial DNA copy number and extracellular matrix (ECM) proteins in the uterosacral ligaments of premenopausal women with pelvic organ prolapse. Taiwanese Journal of Obstetrics and Gynecology. 2016;55(1):9-15.

12. Kim T, Sridharan I, Ma Y, Zhu B, Chi N, Kobak W, et al. Identifying distinct nanoscopic features of native collagen fibrils towards early diagnosis of pelvic organ prolapse. Nanomedicine: Nanotechnology, Biology and Medicine. 2016;12(3):667-75.

13. Ruiz-Zapata AM, Kerkhof MH, Ghazanfari S, Zandieh-Doulabi B, Stoop R, Smit TH, et al. Vaginal Fibroblastic Cells from Women with Pelvic Organ Prolapse Produce Matrices with Increased Stiffness and Collagen Content. Scientific Reports. 2016;6(1).

14. Jean-Charles C, Rubod C, Brieu M, Boukerrou M, Fasel J, Cosson M. Biomechanical properties of prolapsed or non-prolapsed vaginal tissue: impact on genital prolapse surgery. International 
Urogynecology Journal. 2010;21(12):1535-8.

15. Wieslander CK, Marinis SI, Drewes PG, Keller PW, Acevedo JF, RA W. Regulation of Elastolytic Proteases in the Mouse Vagina During Pregnancy, Parturition, and Puerperium. Biol Reprod. 2008;78:521-8.

\section{Figures}

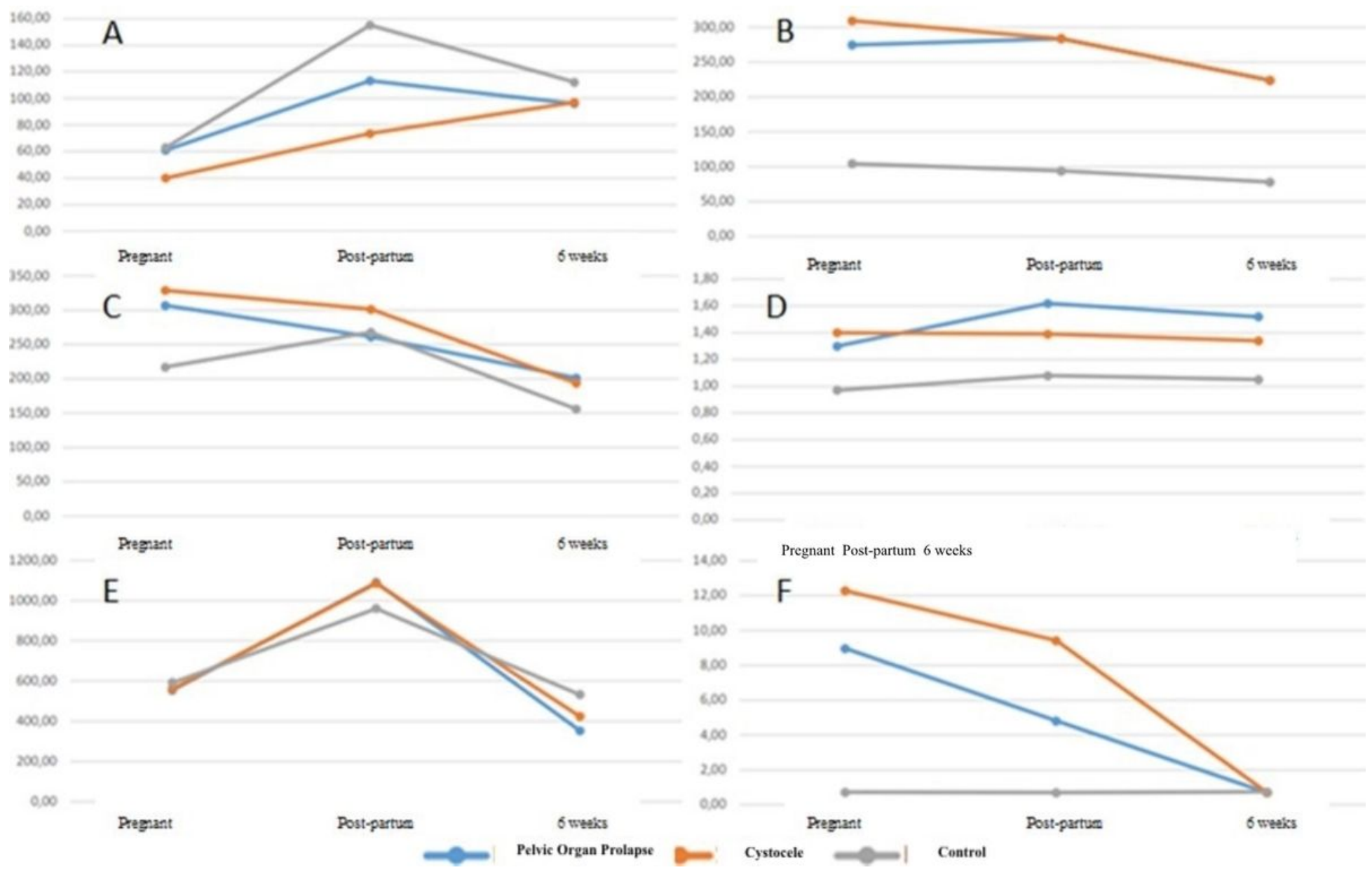

Figure 1

Biomarker levels between pelvic floor dysfunction, cystocele, and control group in pregnancy, after delivery, and 6 weeks postpartum. (A) ICTP, (B) PINP, (C) PIIINP, (D) desmosine, (E) MMP-9, (F) tropoelastin. 